\title{
Industry 4.0: smart test bench for shipbuilding industry
}

\author{
Antonio Giallanza ${ }^{1} \cdot$ Giuseppe Aiello $^{1} \cdot$ Giuseppe Marannano ${ }^{1} \cdot$ Vincenzo Nigrelli $^{1}$
}

Received: 23 September 2020 / Accepted: 6 October 2020 / Published online: 22 October 2020

(c) The Author(s) 2020

\begin{abstract}
Industry 4.0 promises to increase the efficiency of production plants and the quality of the final product. Consequently, companies that implement advanced solutions in production systems will have a competitive advantage in the future. The principles of Industry 4.0 can also be applied to shipyards to transform them into "smart shipyards" (Shipyard 4.0). The aim of this research is to implement an interactive approach by Internet of Things on a closed power-loop test bench equipped with sophisticated sensors that is specifically designed to test high-power thrusters before they are installed on high-speed crafts, which are used in passenger transport. The preliminary results of the proposed Internet of Things-platform demonstrates the efficacy of the decision-making support tool in improving the design of propulsion systems and increasing their efficiency compared to traditional systems.
\end{abstract}

Keywords Industry $4.0 \cdot$ Internet of Things (IoT) $\cdot$ Test bench $\cdot$ CAD modelling $\cdot$ Experimental tests

\section{Introduction}

The term Industry 4.0 (I4.0) was introduced at the Hannover Messe in 2011. It has since received widespread attention from industries and governments around the world $[1,2]$ as it offers significant opportunities to optimise production and development through digitalisation [3]. Consequently, researchers and scholars across the world are closely monitoring the "fourth industrial revolution" [4]. The impact of I4.0 exceeds the frontiers of industrial production and can affect all industrial sectors through the establishment of smart factories $[5,6]$. There are numerous approaches to the digitisation of industry depending on the level of industrialisation in a given country: in developed countries, IT is used to recover or maintain the competitiveness of industry; while in developing countries, industrialisation is linked to digitisation [7]. The enabling technologies of I4.0 can effectively contribute to the digital transformation of an organisation [8-10] with the goal of sustainable development [11-13]. The so-called fourth industrial revolution promises to offer digital technologies that will radically change the traditional architecture of production [14].

Vincenzo Nigrelli

vincenzo.nigrelli@unipa.it

1 Engineering Department - University of Palermo, Viale delle Scienze, 90128 Palermo, Italy
Digital technologies such as the Internet of Things (IoT), cloud computing, big data analytics, etc. can significantly improve the connectivity, communication, and automation in an organisation $[15,16]$. In addition, by using sophisticated sensors, important information can be obtained from process data [17] to improve production [18] and the effectiveness and efficiency of the final products [19]. The principles of I4.0 can also be applied to shipyards [20].

In recent years, several studies have assessed the potential of additive manufacturing [21] in the ship building sector, as it offers several interesting opportunities including weight reduction and performance improvement.

This study evaluates the application of I4.0 at the Liberty Lines shipyard. Liberty Lines S.p.a., is a leading fast ferry operator based in Trapani (Sicily), Italy. A case study on the preliminary transformation of the Liberty Lines shipyard into a shipyard 4.0 is conducted herein. The aim of this study is to improve the performance and sustainability of the shipbuilding industry by optimising a naval propulsion system.

The preliminary implementation of I4.0 technologies is established herein through the design of an IoT platform that can support a test bench that can test and validate an innovative high-power azimuth thruster. The thruster was designed and built at a scale of 1:1. Once tested, the thruster can be installed on a high-speed craft (HSC) for passenger transport. The test bench enables both experimental and final product testing. The use of I4.0 technologies allows the intercon- 
nection of the test system with the network of the company, providing remote control and management of the test system.

The IoT platform and innovative test bench integrate the shipyard production layout with I4.0 logic. To satisfy the current market demands, Liberty Lines have the following objectives: 1) to increase the performance and efficiency of the propulsion plant; 2) to determine a path to gradually improve the green footprint of the organisation; and $3)$ to improve the production processes at the company level. Essentially, these objectives offer a complete digital transformation of manufacturing that not only includes the production and management of the shipyard, but also includes product design and engineering techniques [22]. Furthermore, as the experimental test data can be directly transmitted to the technical office, engineers can analyse the data in real-time and to perform an interactive design to improve the performance of the entire propulsion system or critical system components. Remote control and management are key functionalities that offer the necessary maintenance and control services, and further increase the safety of machines that operate at considerable mechanical stress (high power, high operating pressures, high temperatures, etc.) [23]. The proposed approach allows to create an innovative environment to support the interactive engineering with design and development phases that are performed in parallel rather than in series in order to reduce production time and costs. Thus, I4.0 offers numerous challenges and opportunities to industries (e.g., resource efficiency, costs, work organisation, and synchronisation between ICT-Information and Communications Technology—and people) to achieve sustainable development [24]. Increases in the efficiency and effectiveness of the propulsion system can allow shipping companies to install environmentally-friendly high-performance propulsion systems with long life-cycles on naval units, thereby reducing operating costs and increasing profitability. In addition to improving the monitoring of the propulsion system during its operation [25-28], these factors contribute to the innovations offered by I4.0 to the shipbuilding industry (Shipping 4.0).

\section{Case study}

\subsection{The thruster system}

Over the past decade, shipping companies have shown a renewed interest in high-speed crafts (HSCs), especially for short-haul passenger transport. Hydrofoils have not evolved significantly in decades and have been set aside by the industry, while HSCs have become competitive again due to several important technological innovations [29-32]. Furthermore, the use of light-weight and strong materials such as

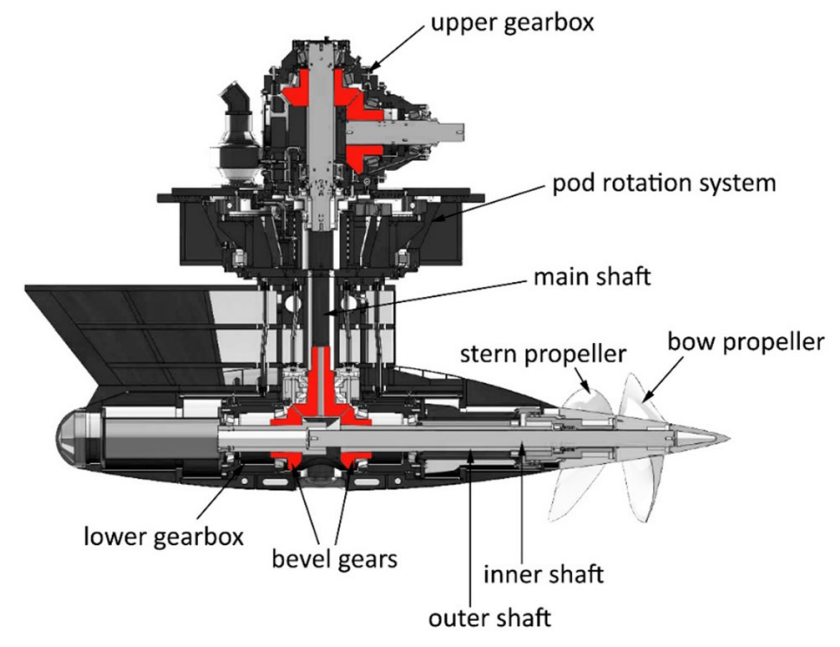

Fig. 1 Kinematic configuration of the studied POD drivetrain

fibre metal laminates or composite sandwich materials have led to significant reductions in weight [33-37].

The thruster studied herein is realised in a C-drive configuration, with an engine power of around $2000 \mathrm{~kW}$ and a rotation speed of around $1000 \mathrm{rpm}$. The first reduction is obtained by a bevel gear housed inside an aluminium alloy box inside the hull (upper gearbox in Fig. 1), and a second reduction is realised by bevel gears housed inside a profiled box located in the lower end of the stern strut. Propeller shafts in a contra-rotating configuration are installed in the lower gearbox.

The designed thruster not only provides propulsive thrust, but also allows azimuthal rotation to provide maximum manoeuvrability in port and cruise control in high-speed crafts, monohulls, or catamarans at $15-40$ knots. The design solution was identified after a thorough study of several alternatives and is the most suitable solution for rapid and precise rotation of the struts and effective control of the naval unit.

The azimuthal rotation of the thruster is performed by two double-acting hydraulic actuators (Fig. 2) whose ends are connected to the hull structure and the strut, respectively. This increases the simplicity of construction and contributes to the reductions in the overall weight and cost.

The azimuthal rotation of the PODs enables highprecision steering of the vessel and eliminates the need for rudders.

The kinematic configuration of the drivetrain inside the lower gearbox (Fig. 1) consists of two contra-rotating shafts on which the two propellers are fitted. On the ends of the shafts housed inside the gearbox are two bevel gears that are rotated by a gear fitted on the main shaft, which rotates inside the strut.

To reduce the size and weight of the shafts, the gears and propellers are mounted on the shafts through an interference fit. The interference fit has been in use for several years and 


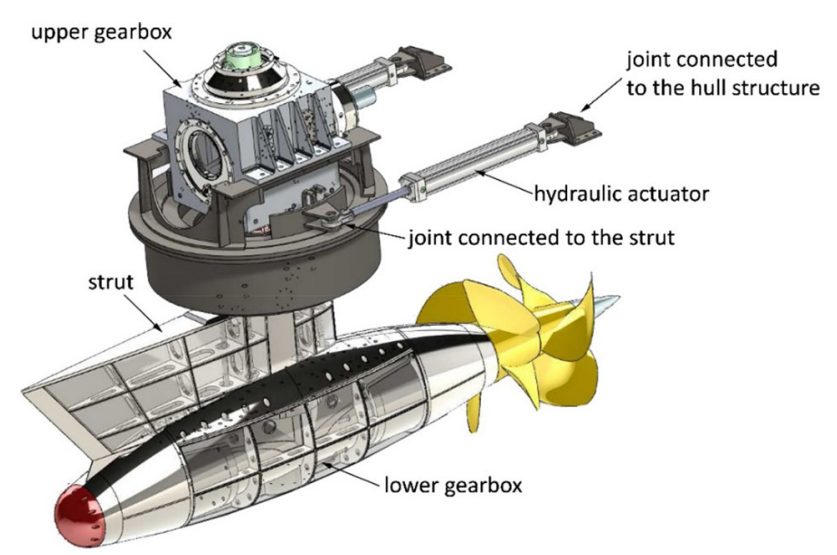

Fig. 2 Configuration of the pod rotation system

offers high reliability in the transmission of high torsional loads. Invariably, this type of coupling is the only solution to connect a hub to the shaft in the presence of variable loads. Tightening during assembly is performed by means of an oil pump system (oil injection method) that expands the propellers or wheel hub. To do so, the shafts must be equipped with helical ducts and oil grooves. Injecting oil between two tapered surfaces creates a thin oil film that reduces the friction between them and significantly reduces the mounting force required. The thin oil film also reduces the risk of component damage. The system is also used during the process of extracting the propeller or gears; the injected oil reduces the required extraction force by up to $90 \%$.

Composite materials with carbon fibres and epoxy resin were used for the drive shaft inside the hull, which is the shaft that connects the output of the inverter to the upper gearbox; the latter was fabricated using an aluminium alloy casting process. The struts connecting the lower gearbox of the thruster to the hull were realised using a boxed and welded steel structure, while the lower gearbox containing the transmission components was made of cast EN $43300 \mathrm{~T} 6$ aluminium, to reduce costs and increase the speed of production. The inner bearing seats were machined by computerised numerical control machines to allow the housing of the shafts of the contra-rotating propeller system.

High-strength steel was used to construct the gear wheels and contra-rotating shafts in the lower gearbox. Furthermore, during this research, robust solutions were identified for the seals positioned at the output of the contra-rotating shafts near the propellers and those positioned at the POD rotation system that provides thrust orientation.

\subsection{The test bench}

To determine the performance of the system, the thruster must be operated at full-load and maximum rotation speed. Ideally, the gearbox should be tested under the exact same

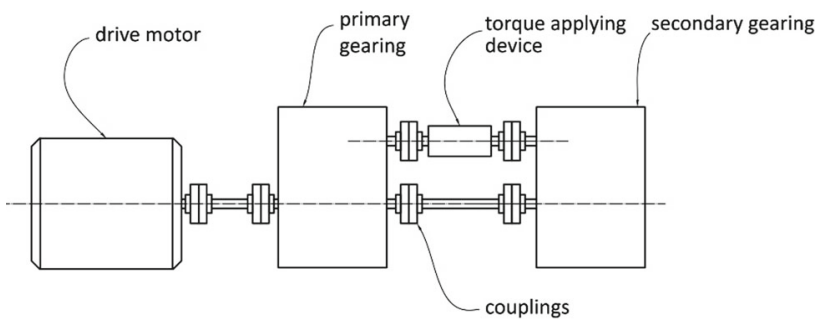

Fig. 3 General layout of the mechanical closed power loop test bench

conditions it would encounter during actual use. However, reliable reproductions of actual conditions in laboratory environments are often impractical.

The technique of transmitting the maximal power through a gearbox by performing the actual application is known as a power dissipation test. When the rotation speeds and rated power of a given transmission are relatively low, the power dissipation test is preferred to other solutions, which are often more expensive. However, when the rated power of the gearbox is high, the power dissipation test is often impractical as it requires the use of a motor unit and a high power braking unit. This can increase the cost of the test equipment, and a large amount of power must be dissipated using a hydraulic brake [38] or dynamometer during testing.

Closed power loop test benches enable the testing of transmissions with a high rated power at relatively low operating costs. This type of mechanical test bench requires the implementation of a back-to-back connection between two identical gearing sets (primary and secondary, see Fig. 3). The two gearsets to be tested were connected to each other in a closed loop circuit and the rotation of the connecting shafts was started, after which a mechanical system (torque-applying device) applied the torque generated during operation.

The torque-applying device was specifically designed for this study. Existing devices have several differences in terms of their mechanical and hydraulic systems. The designed torque-applying device also differs from those available in existing literature [39], in that the relative rotation of the end flanges, which generates the test torque, is achieved by means of an innovative kinematic system (patent application number: 102019000011031). The main advantage of the torque-applying device developed herein is that unlike those in existing literature, the components are not subjected to significant centrifugal forces due to the effect of rotation. Moreover, the device does not require a rotating distributor as the hydraulic cylinder is positioned outside the machine in a fixed position and is not subjected to any rotation. The necessary thrust is generated by means of a leverage to realise the test torque. Notably, the system developed herein is more compact and less expensive as the hydraulic actuator can be selected from those available on the market. 


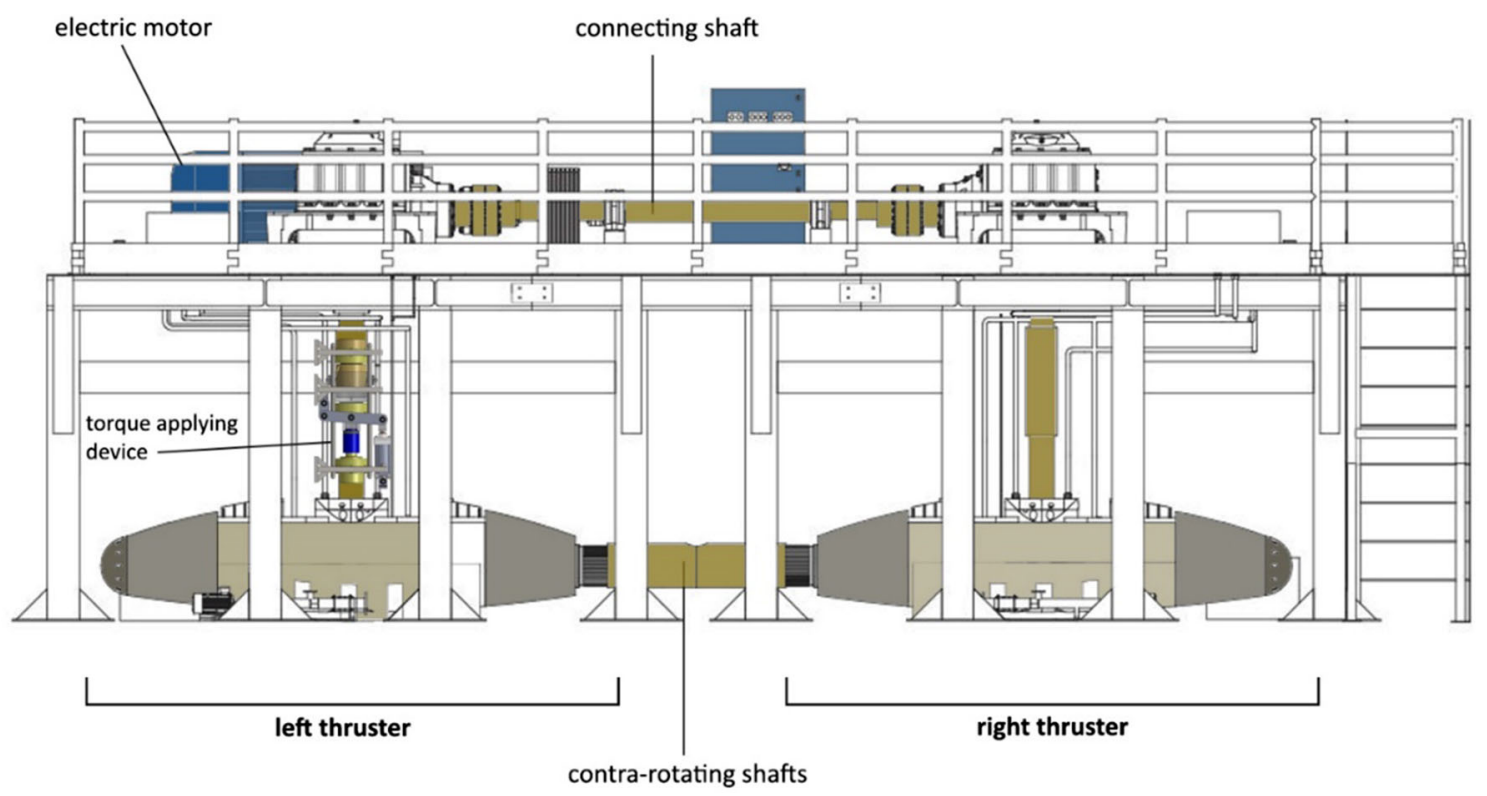

Fig. 4 CAD model of the test bench

Fig. 5 Overview of the assembled test bench

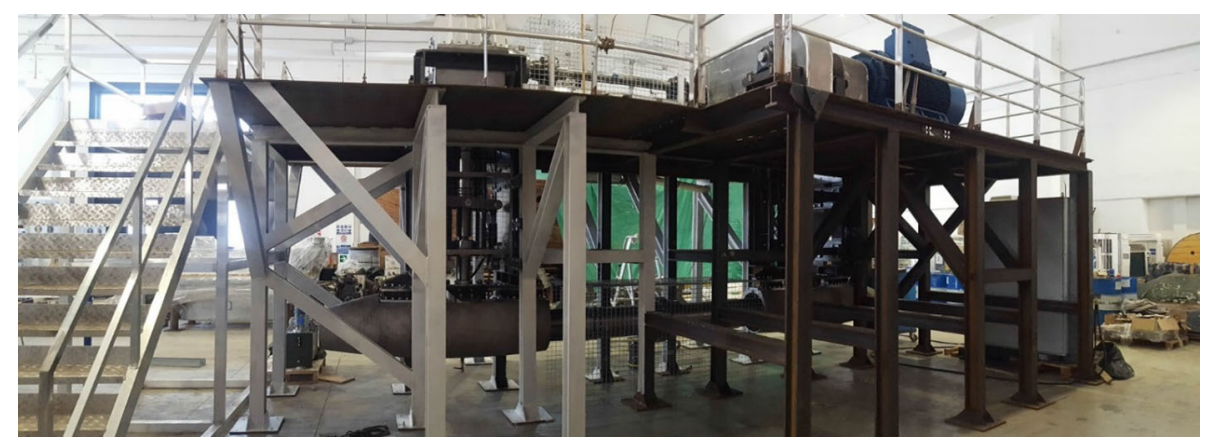

Figures 4 and 5 show a front view of the designed test bench in the back-to-back configuration and an overview of the assembled test bench, respectively.

Figure 6 shows the torque-applying device that generates the torque.

An electric motor with a maximum power of $300 \mathrm{~kW}$ was used to move the shafts of the two thrusters. The maximum rotation speed was $990 \mathrm{rpm}$. Figure 7 shows the connection between the motor shaft and the kinematic chain using 8 belts.

\subsection{IoT platform}

As mentioned previously, the test bench evaluates the effectiveness and efficiency of the propulsion system, which is one of the most critical components of a naval unit. In the absence of experimental tests, it is entirely possible that a new propulsion system installed on a naval unit could be damaged within a few hours of operation. This would cause significant hardship to the ship-owner, affecting service and resulting in lost profit and reputation. This, in addition to the fact that multiple external companies are generally involved in the production of the various components of the propulsion system, makes the experimental tests performed on the test bench extremely important.

The development of a smart IoT platform connected to the test bench can help integrate the data detected by the sensors, enabling the quick solution of critical issues that may arise after the design and/or realisation of the thruster components. Therefore, several aspects must be addressed in the definition of the IoT platform.

In particular, the macro-functionalities implemented in the platform must include:

1) The thruster components (drawings, technical specifications, computer-aided design (CAD) models, etc.)

2) The control parameters during the test run (rotation speed, rated power, applied torque, etc.)

3) The real-time values (and maximum values) of temperature, pressure, and strain 


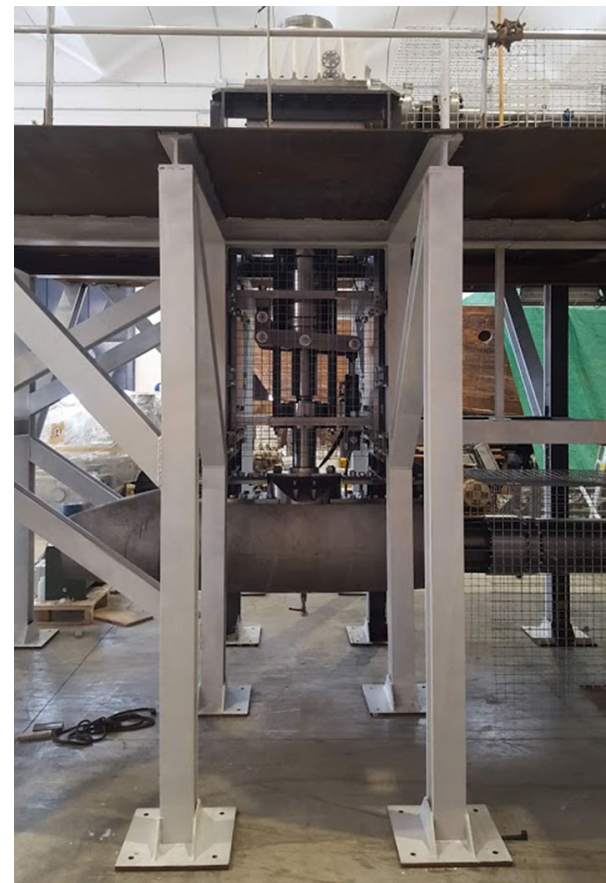

Fig. 6 Torque-applying device installed on the test bench

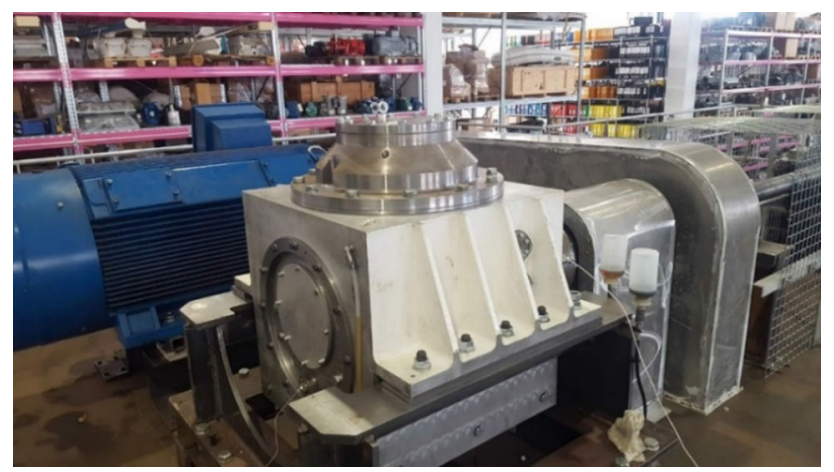

Fig. 7 Connection between the electric motor and the test kinematic chain

4) Information regarding the manufacturer of a specific component (the shipyard or an external company).

Another feature is the activation of specific alerts that inform the user when the values measured by the sensors exceed the limit thresholds. Furthermore, a graphic comparison (pie charts, bar charts, etc.) of the experimental data recorded after each test can provide the information required to evaluate the improvements in system efficiency.

\section{Experimental tests and data analysis}

The torque values were measured using strain gauge rosettes (Fig. 8) and torque transducers were installed on the drive

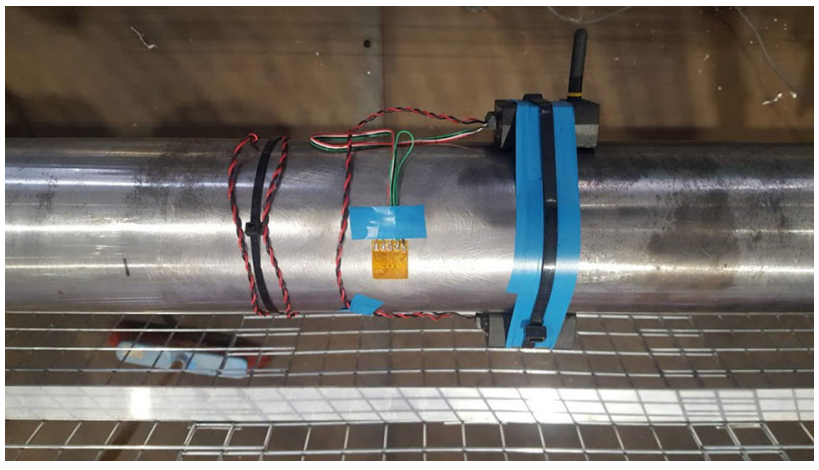

Fig. 8 Wireless torque sensor for rotary torque measurement

shafts. Electrical strain gauges were connected to the wireless torque transmitter, which sent the signal to the receiver installed on a workstation. This setup provides accurate and reliable torque data.

Electrical strain gauges were also installed on the test bench frame and the pod struts to compare the strain recorded during the experiment with that obtained from finite element analyses [40-43].

Optimum lubrication of the transmission components during power transmission plays a key role in the proper functioning and long service life of the roller bearings. Essentially, lubrication creates a film that separates the two contact surfaces, preventing wear and premature fatigue failure. In addition, proper lubrication extracts heat from the internal elements, allows proper heat exchange, and ensures that the bearing works at optimum operating temperatures during its service life. Quick identification of a sudden increase in temperature can prevent bearing damage and the resulting failure of the thruster.

The cylindrical roller bearings and the single row tapered roller bearings in the thruster are thermally stabilised up to temperatures of $150{ }^{\circ} \mathrm{C}$. Therefore, this value represents a limit beyond which the rolling elements would be damaged or the raceways would experience rapid wear, thereby compromising the operating quality of the thruster.

Temperature data are influenced by the heat exchange that occurs with the air-conditioned laboratory environment during the experiment, and the heat exchange that occurs with water during actual operation. However, this study evaluates both the geometric configuration and the lubrication conditions, leading to a more functional use of the roller bearings selected to support the transmission shafts. Appropriate lubricating oil injectors (Fig. 9) that provided punctual and precise lubrication of the parts subjected to wear were used to lubricate the bearings and bevel gears of the upper gearbox. In particular, compared to splash lubrication (oil bath method), the experimental results demonstrated a reduction of approximately $15 \%$ of the dissipated power. 


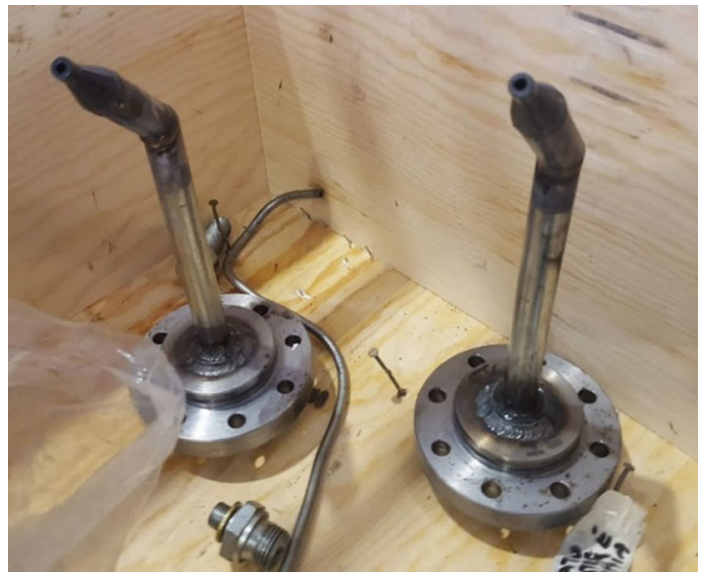

Fig. 9 Injectors used for the lubrication of the upper gearbox transmission components

Figure 10 denotes the positions at which eight PT100 thermo-resistance sensors were installed to detect the instantaneous temperature during operation. Four sensors were positioned on the bearings of the upper gearbox (sensors T1, $\mathrm{T} 2$, T5, and T6), while the other four were installed on the cylindrical roller bearings positioned near the contra-rotating propellers (sensors T3, T4, T7, and T8).

The cylindrical roller bearings on which sensors T3, T4, $\mathrm{T} 7$, and $\mathrm{T} 8$ were installed prevent the optimal lubricant supply required on the contact points between the rolling elements and the raceways due to their proximity to the thruster propellers.

At the maximum motor power and rotation speeds of close to $1000 \mathrm{rpm}$, the possibility of optimal heat dissipation from

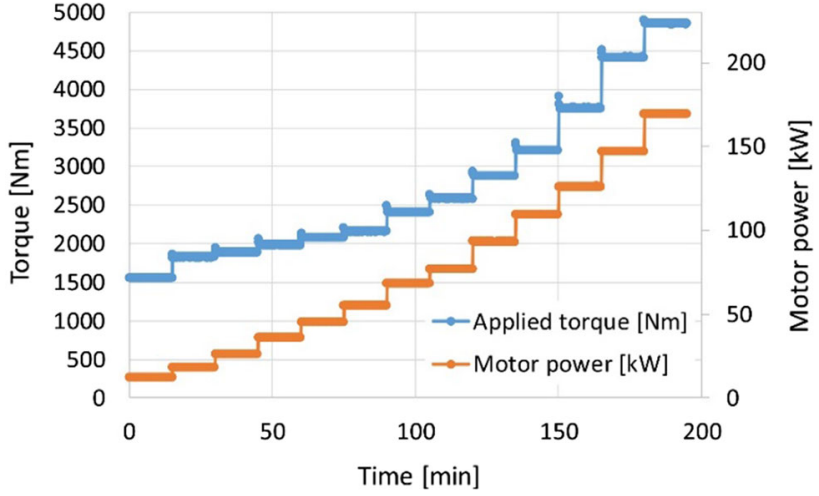

Fig. 11 Trends of the applied torque and motor power during the experiments

the bearing is drastically reduced. To ensure the operational life of the bearing, more expensive supply and sealing systems are required. These supply ducts should be as short as possible, face the lubrication holes of the roller bearings directly, and provide a separate duct for each bearing.

Using the test bench to test the validity of the proposed solutions, the oil inlet ducts were redesigned. This increased the heat dissipation capacity. Several tests were conducted at various torque values using the torque-applying device. Initially, the electric motor was operated with no load, i.e., without the introduction of torque in the closed-loop circuit. Without additional torque, the power provided by the electric motor must only overcome the friction in the bearings and gear wheels. The system was kept in rotation for an initial duration of $10 \mathrm{~min}$. Subsequently, torque was introduced according to the load diagram shown in Fig. 11. The figure
Fig. 10 Location of temperature sensors on the thrusters

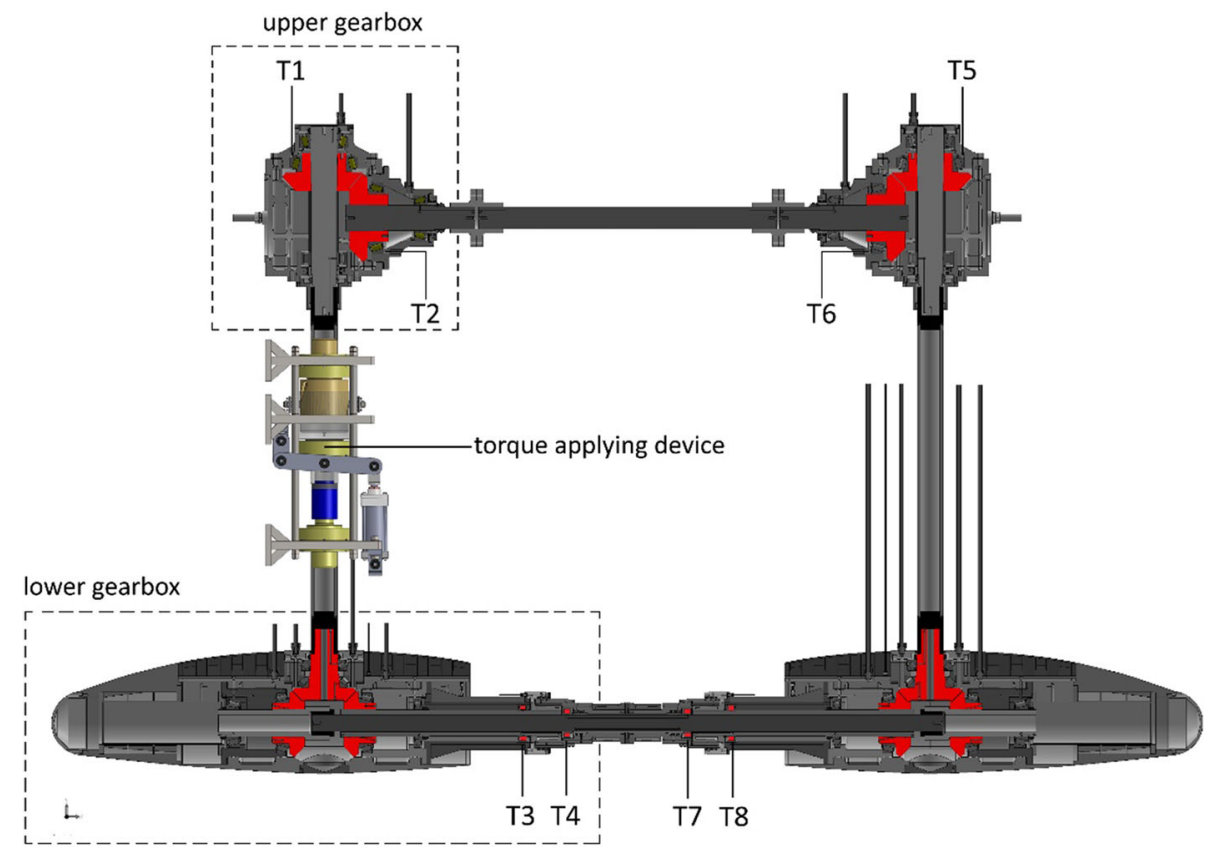




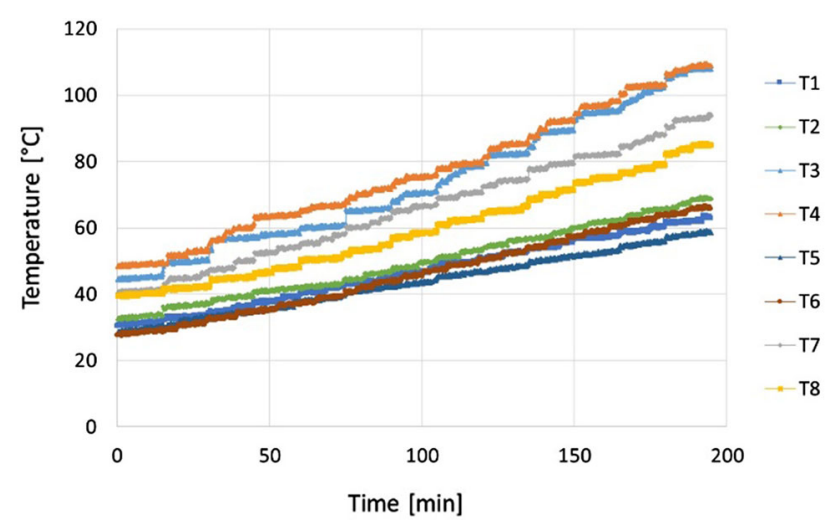

Fig. 12 Temperature values recorded by the eight sensors during the experiments

illustrates the trend of the torque introduced into the system and the power values of the electric motor with time. The total test duration was approximately $3 \mathrm{~h}$, during which the two thrusters continued to rotate under the applied load.

Figure 12 shows the temperature values recorded by the eight sensors installed on the roller bearings (Fig. 10).

As shown in Fig. 12, sensors T3 and T4 recorded nonoptimal temperature values towards the end of the test due to the inadequate lubrication of the bearings. Therefore, the oil supply ducts must be redesigned to ensure adequate dissipation of the heat produced during the load test. A screenshot of the IoT platform is shown in Fig. 13. The figure shows

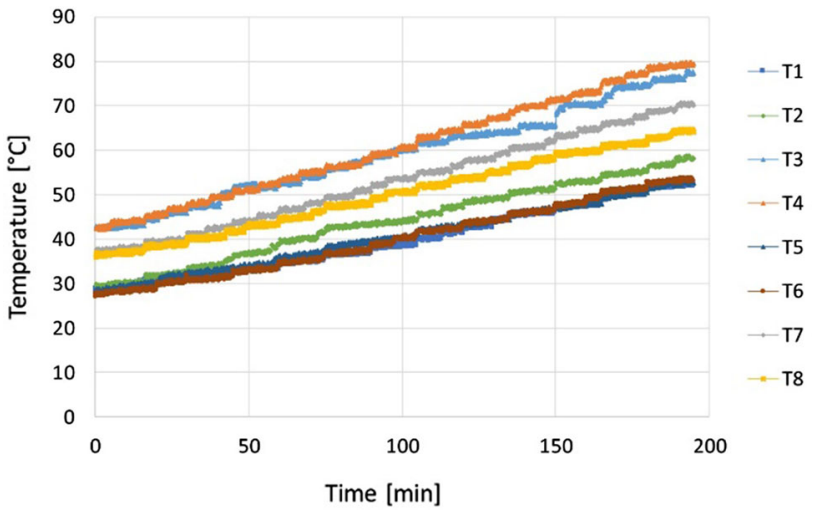

Fig. 14 Temperature values recorded by the eight sensors during the experiments after redesigning the oil supply ducts

the real-time display of the temperature data recorded by the eight sensors. Notably, the IoT platform enables the recording of data during the tests, and a comparison and analysis of the results of different tests.

Figure 14 shows the trend of the temperature values recorded by the eight sensors after repositioning the lubricating oil injectors and redesigning the oil supply ducts.

As shown in Fig. 14, considering the temperature values recorded by sensor $\mathrm{T} 4$ towards the end of the experimental, the redesign of the lubrication system reduces the temperature of the bearing by approximately $27 \%$.
Fig. 13 The IoT platform: real-time display of the temperature recorded by the eight sensors

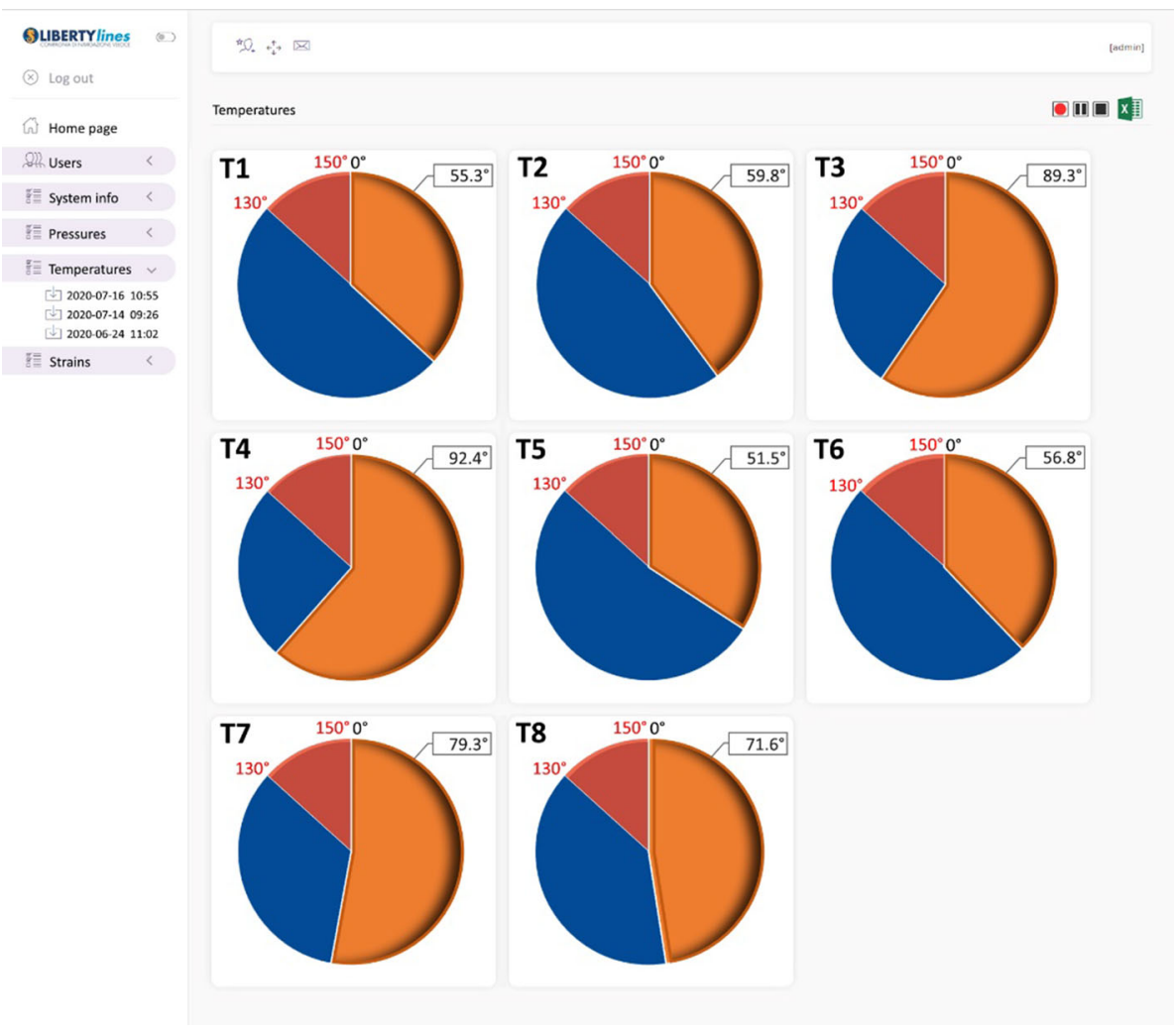




\section{Conclusions}

The preliminary implementation of I4.0 on a prototype test bench for a high-power azimuth thruster under full load conditions was studied, designed, and validated. To set up the test bench with I4.0 capabilities, IoT sensors were used to collect and record the data, and a decision-making support tool was developed. The research objects- the test bench and the azimuth thruster-were equipped with the sensors to record the data to be analysed. Subsequently, data analysis was used to evaluate the efficiency of the product and the operating process. After testing and validation, the azimuth thruster can be installed on a high-speed craft for passenger transport. In accordance with previous experimental results, the main parameters that affect the efficiency of the system - the strain of the mechanical parts, the operating pressure, and the temperature-were recorded herein.

Based on the analysis and processing of the temperature data recorded during the tests, the oil supply ducts were redesigned and the lubricating oil injectors were repositioned. This decreased the temperature of the roller bearings by approximately $27 \%$. Moreover, compared to splash lubrication (oil bath method), the optimisation of the lubricating oil injection method in the upper gearbox reduced the power dissipation by approximately $15 \%$. These results not only increase the life of the transmission components, but also increase the effectiveness and efficiency of the entire propulsion system. Additional advantages include a decrease in noise levels and vibrations, compactness, and reductions in weight, fuel consumption, installation, and maintenance costs. The used approach contributes to the development of an innovative environment to support the interactive engineering where the design and development phases are performed in parallel rather than in series in order to reduce production time and costs.

In conclusion, the preliminary results obtained using the IoT platform can help the company to achieve its goal of improving the performance, efficiency, and sustainability of the propulsion system. To fully exploit the potential of the IoT platform developed herein, further studies must be conducted to manage the entire production process of the naval unit and interconnect the platform with business management systems.

Future studies will focus on the realisation of a digital replica of the propulsion plant that can overcome the limits of traditional design, which requires several expensive experimental tests to validate the project.

Acknowledgements This work has been supported by the project "AQUAPROP: Sistema POD di propulsione innovativo ed ecocompatibile per applicazione commerciale su imbarcazioni veloci adibite a trasporto passeggero" funded by the MIT-Ministero delle Infrastrutture e dei Trasporti, grant n. 8409.
Funding Open access funding provided by Università degli Studi di Palermo within the CRUI-CARE Agreement.

Open Access This article is licensed under a Creative Commons Attribution 4.0 International License, which permits use, sharing, adaptation, distribution and reproduction in any medium or format, as long as you give appropriate credit to the original author(s) and the source, provide a link to the Creative Commons licence, and indicate if changes were made. The images or other third party material in this article are included in the article's Creative Commons licence, unless indicated otherwise in a credit line to the material. If material is not included in the article's Creative Commons licence and your intended use is not permitted by statutory regulation or exceeds the permitted use, you will need to obtain permission directly from the copyright holder. To view a copy of this licence, visit http://creativecomm ons.org/licenses/by/4.0/.

\section{References}

1. Ghobakhloo, M.: The future of manufacturing industry: a strategic roadmap toward industry 4.0. J. Manuf. Technol. Manag. 29(6), 910-936 (2018)

2. Nascimento, D.L.M., Alencastro, V., Quelhas, O.L.G., Caiado, R.G.G., Garza-Reyes, J.A., Rocha-Lona, L., Tortorella, G.: Exploring Industry 4.0 technologies to enable circular economy practices in a manufacturing context: a business model proposal. J. Manuf. Technol. Manage. 30(3), 607-627 (2019)

3. Da Costa, M.B., Dos Santos, L.M.A.L., Schaefer, J.L., Baierle, I.C., Nara, E.O.B.: Industry 4.0 technologies basic network identification. Scientometrics 121(2), 977-994 (2019)

4. Liao, Y., Deschamps, F., Loures, E.F.R., Ramos, L.F.P.: Past, present and future of industry 4.0 - a systematic literature review and research agenda proposal. Int. J. Product. Res. 55(12), 3609-3629 (2017)

5. Yin, Y., Kathryn E. Stecke, K.E., Li, D.: The evolution of production systems from industry 2.0 through industry 4.0. Int. J. Product. Res. 56(1-2), 848-861 (2018)

6. Xu, L.D., Xu, E.L., Li, L.: Industry 4.0: state of the art and future trends. Int. J. Product. Res. 56(8), 2941-2962 (2018)

7. Li, Q., Tang, Q., Chan, I., Wei, H., Pu, Y., Jiang, H., Li, J., Zhou, J.: Smart manufacturing standardization: architectures, reference models and standards framework. Comput. Ind. 101, 91-106 (2018)

8. Basl, J.: Pilot study of readiness of czech companies to implement the principles of industry 4.0. Manage. Product. Eng. Rev. 8(2), 3-8 (2017)

9. Khan, M., Wu, X., Xu, X., Dou, W.: Big data challenges and opportunities in the hype of industry 4.0. In: IEEE International Conference on Communications. (2017)

10. Duarte, S., Cruz-Machado V.: Exploring Linkages Between Lean and Green Supply Chain and the Industry 4.0. In: International Conference on Management Science and Engineering Management. (2017)

11. de Sousa Jabbour, A.B.L., Jabbour, C.J.C., Foropon, C., Filho, M.G.: When titans meet - can industry 4.0 revolutionise the environmentally-sustainable manufacturing wave? The role of critical success factors. Technol. Forecast Soc. Change. 132, 18-25 (2018)

12. Piccarozzi, M., Aquilani, B., Gatti, C.: Industry 4.0 in Management Studies: a Systematic Literature Review. Sustainability 10, 3821 (2018) 
13. Müller, J.M., Kiel, D., Voigt, K.I.: What drives the implementation of Industry 4.0? the role of opportunities and challenges in the context of sustainability. Sustainability 10, 247 (2018)

14. Telukdarie, A., Buhulaiga, E.A., Bag, S., Gupta, S., Luo, Z.: Industry 4.0 implementation for multinationals. Process Safety Environ. Protect. 118, 316-329 (2018)

15. Ardolino, M., Rapaccini, M., Saccani, N., Gaiardelli, P., Crespi, G., Ruggeri, C.: The role of digital technologies for the service transformation of industrial companies. Int. J. Product. Res. 56(6), 2116-2132 (2018)

16. Ivanov, D.A., Dolgui, A., Sokolov, B.: The impact of digital technology and industry 4.0 on the ripple effect and supply chain risk analytics. Int. J. Product. Res. 57(3), 829-846 (2019)

17. Tao, F., Qi, Q., Liu, A., Andrew Kusiak, A.: Data-driven smart manufacturing. J. Manuf. Syst. 48, 157-169 (2018)

18. Frank, A.G., Dalenogare, L.S., Ayala, N.F.: Industry 4.0 technologies: implementation patterns in manufacturing companies. Int. J. Product. Econ. 210, 15-26 (2019)

19. Hofmann, E., Rüsch, M.: Industry 4.0 and the current status as well as future prospects on logistics. Comput. Ind. 89, 23-34 (2017)

20. Munín-Doce, A., Díaz-Casás, V., Trueba, P., Ferreno-González, S., Vilar-Montesinos, M.A.: Industrial internet of things in the production environment of a shipyard 4.0. Int. J. Adv. Manuf. Technol. 108(1-2), 47-59 (2020)

21. Ingrassia, T., Nigrelli, V., Ricotta, V., Tartamella, C.: Process parameters influence in additive manufacturing. Lecture Notes Mech. Eng. (2017). https://doi.org/10.1007/978-3-319-45781-9_2 7

22. Neuhofer, B., Buhalis, D., Ladkin, A.: Smart technologies for personalized experiences: a case study in the hospitality domain. Electr. Markets 25(3), 243-254 (2015)

23. Ruppert, T., Jaskó, S., Holczinger, T., Abonyi, J.: Enabling technologies for operator 4.0: a survey. Appl. Sci. (2018). https://doi. org/10.3390/app8091650

24. Stock, T., Seliger, G.: Opportunities of sustainable manufacturing in industry 4.0. Proc. CIRP. 40, 536-541 (2016)

25. Aiello, G., Giallanza, A., Vacante, S., Fasoli, S., Mascarella, G.: Propulsion monitoring system for digitized ship management: preliminary results from a case study. Proc. Manuf. 42, 16-23 (2020)

26. Aiello, G., Giallanza, A., Mascarella, G.: Towards shipping 4.0. A preliminary gap analysis. Proc. Manuf. 42, 24-29 (2020)

27. Bocchetti, D., Lepore, A., Palumbo, B., Vitiello, L.: A statistical approach to ship fuel consumption monitoring. J. Ship Res. 59(3), 162-171 (2015)

28. Erto, P., Lepore, A., Palumbo, B., Vitiello, L.: A procedure for predicting and controlling the ship fuel consumption: its implementation and test. Quality Reliab. Eng. Int. 31(7), 1177-1184 (2015)

29. Giallanza, A., Marannano, G., Morace, F., Ruggiero, V.: Numerical and experimental analysis of a high innovative hydrofoil. Int. J. Interact. Des. Manuf. 14(1), 43-57 (2020)
30. Giallanza, A., Cannizzaro, L., Porretto, M., Marannano, G.: Design of the stabilization control system of a high-speed craft. Lecture Notes Mech. Eng. (2017). https://doi.org/10.1007/978-3-319-457 81-9_58

31. Cannizzaro, L., Giallanza, A., Marannano, G., Muraca, E., Palladino, M.: Dual compensation control-system for offshore logistic equipment. In: NAV International Conference on Ship and Shipping Research. (2012)

32. Giallanza, A., Marannano, G., Pasta, A.: Structural optimization of innovative rudder for HSC. In: NAV International Conference on Ship and Shipping Research. (2012)

33. Marannano, G., Virzì Mariotti, G.: Structural optimization and experimental analysis of composite material panels for naval use. Meccanica 43(2), 251-262 (2008)

34. Ingrassia, T., Alaimo, G., Cappello, F., Mancuso, A., Nigrelli, V.: A new design approach to the use of composite materials for heavy transport vehicles. Int. J. Veh. Des. 44(3-4), 311-325 (2007)

35. Giallanza, A., Parrinello, P., Ruggiero, V., Marannano, G.: Fatigue crack growth of new FML composites for light ship buildings under predominant mode II loading condition. Int. J. Interact. Des. Manuf. 14(1), 77-87 (2020)

36. Tumino, D., Ingrassia, T., Nigrelli, V., Pitarresi, G., Urso Miano, V.: Mechanical behavior of a sandwich with corrugated GRP core: numerical modeling and experimental validation. Frattura ed Integrità Strutturale 30, 317-326 (2014)

37. Marannano, G., Pasta, A., Giallanza, A.: A model for predicting the mixed-mode fatigue crack growth in a bonded joint. Fatigue Fract. Eng. Mater. Struct. 37(4), 380-390 (2014)

38. Baron Saiz, C., Ingrassia, T., Nigrelli, V., Ricotta, V.: Thermal stress analysis of different full and ventilated disc brakes. Frattura ed Integrità Strutturale 9(34), 608-621 (2015)

39. Collins, L.J.: Torque applying device. Patent US2371607 (1945)

40. Cucinotta, F., Nigrelli, V., Sfravara, F.: Numerical prediction of ventilated planing flat plates for the design of Air Cavity Ships. Int. J. Inter. Des. Manuf. 12(2), 537-548 (2018)

41. Cirello, A., Cucinotta, F., Ingrassia, T., Nigrelli, V., Sfravara, F.: Fluid-structure interaction of downwind sails: a new computational method. J. Mar. Sci. Technol. Jpn. 24(1), 86-97 (2019)

42. Mirulla, A.I., Bragonzoni, L., Zaffagnini, S., Bontempi, M., Nigrelli, V., Ingrassia, T.: Virtual simulation of an osseointegrated trans-humeral prosthesis: a falling scenario. Injury 49(4), 784-791 (2018)

43. Cucinotta, F., Nigrelli, V., Sfravara, F.: A preliminary method for the numerical prediction of the behavior of air bubbles in the design of air cavity ships. Lecture Notes Mech Eng (2017). https://doi.org/ 10.1007/978-3-319-45781-9_51

Publisher's Note Springer Nature remains neutral with regard to jurisdictional claims in published maps and institutional affiliations. 